www.nature.com/pj

\title{
Utilization of milk protein as an environmental material: accumulation of metal ions using a protein-inorganic hybrid material
}

\author{
Masanori Yamada and Mayuna Tsuruzumi
}

Casein is a well-known phosphoprotein that possesses many metal ion-binding sites in its molecular structure; thus, a caseincontaining hybrid material can be used for accumulating metal ions from an aqueous solution. A casein-inorganic hybrid material was prepared by mixing casein and a silane coupling reagent, bis[3-(trimethoxysilyl)propyl]amine. This casein-inorganic hybrid material was stable in an aqueous solution owing to the electrostatic interactions between the phosphate group in casein and the amino group in the silane coupling reagent. When the casein-inorganic hybrid material was incubated in an aqueous $\mathrm{Cu}(\mathrm{II})$ ion-containing solution, the hybrid material turned blue owing to the accumulation of the $\mathrm{Cu}$ (II) ions. Therefore, we demonstrated the accumulation of various metal ions using the casein-inorganic hybrid material from aqueous solutions. The hybrid materials could selectively accumulate heavy and light metal ions and did not interact with the rare-earth metal ions. In addition, the metal ion-accumulated casein-inorganic hybrid materials could be recycled by washing with an aqueous EDTA solution or hydrochloric acid.

Polymer Journal (2016) 48, 295-300; doi:10.1038/pj.2015.113; published online 2 December 2015

\section{INTRODUCTION}

Casein is a well-known phosphoprotein that is commonly found in mammalian milk, accounting for $80 \%$ of the proteins in cow's milk. ${ }^{1,2}$ As many serine residues in casein have replaced the phosphate group, the net charge of casein in milk is negative. Therefore, owing to the binding between calcium and the phosphate group, casein forms a micelle structure with diameters ranging from 40 to $300 \mathrm{~nm}$ in milk. ${ }^{1}$ In addition, because the isoelectric point of casein is $\sim 4.6$, it releases the calcium ion from the structure at $\mathrm{pH} 4.6$ and then precipitates. Casein has properties of not only a nutrient but also a stabilizer. ${ }^{1}$ Furthermore, casein consists of amino acids and thus possesses many reactive functional groups, such as amino groups, carboxyl groups and hydroxyl groups. Therefore, casein has been used as a stabilizer for foodstuffs, casein plastics, paints and so on. ${ }^{1,3,4}$ Furthermore, casein possesses many metal ion-binding sites in its molecular structure, and these binding sites can have a role in the absorption of metal ions, such as heavy metal and rare metal ions. ${ }^{5-8}$ These properties of casein might allow its use as an environmental material, such as for the accumulation of metal ions. However, because casein is unstable under environmental conditions and cannot be used for a long period, the utilization of casein as an environmental material requires hybridization with other materials.

Organic-inorganic hybrid material has become attractive because it possesses the flexibility of an organic component and the mechanical strength of an inorganic component. ${ }^{9-11}$ As the organic-inorganic hybrid material is synthesized through sol-gel processes, the hybrid material can be fabricated with biological molecules and inorganic components. Organic-inorganic hybrid materials containing a biological molecule, such as a protein, polysaccharide or nucleic acid, have been reported as being used for the adsorption of harmful compounds, ${ }^{12-14}$ as a proton-conducting material ${ }^{15,16}$ and as bio- and medical materials ${ }^{17,18}$ among other applications. ${ }^{19,20}$ Therefore, in this research, we demonstrated the utilization of milk protein-inorganic hybrid material as an environmental material, that is, as an absorbent for heavy metal ions.

In this study, we prepared casein-inorganic hybrid material by mixing casein and the silane coupling reagent, bis[3-(trimethoxysilyl) propyl] amine (SiNSi). The casein-SiNSi hybrid material was stable in an aqueous solution. In addition, the casein-SiNSi hybrid material could selectively accumulate heavy and light metal ions. Furthermore, the metal ion-accumulated casein-SiNSi hybrid material could be recycled by washing it with an aqueous EDTA solution or hydrochloric acid. According to infrared (IR) spectrometry, the accumulation of metal ions was related to the phosphate and carboxylate groups in casein.

\section{EXPERIMENTAL PROCEDURE \\ Material}

Casein (from milk) was purchased from Wako Pure Chemical Industries, Ltd., Osaka, Japan. The silane coupling reagent, bis[3-(trimethoxysilyl)propyl]amine (SiNSi), was purchased from Tokyo Kasei Industries Ltd., Tokyo, Japan. Copper(II) chloride, zinc(II) chloride, chromium(III) chloride, aluminum 
chloride, calcium chloride, magnesium chloride, yttrium(III) chloride, lanthanum(III) chloride, indium(III) chloride, xylenol orange, methylthymol blue, and ethylenediamine- $N, N, N^{\prime}, N^{\prime}$-tetraacetic acid disodium salt dihydrate were obtained from Wako Pure Chemical Industries Ltd., Kanto Chemical Co., Inc., Tokyo, Japan or Dojindo Co., Kumamoto, Japan. Analytical grade solvents were used in all of the experiments described. Ultra-pure water (Merck KGaA, Darmstadt, Germany) was used in this experiment.

\section{Preparation of the casein-SiNSi hybrid material}

Casein $(3 \mathrm{~g})$ was dissolved in water $(30 \mathrm{ml})$ along with a $28 \%$ ammonium solution $(150 \mu \mathrm{l})$. The casein-SiNSi hybrid material was prepared as follows. The casein solution $(1 \mathrm{ml})$ and the SiNSi solution $(0-233 \mu \mathrm{l})$ were mixed in a microtube. In these experiments, the mixing ratio of casein/SiNSi was varied from 100:0 (wt $\% / w t \%)$ to 30:70 (wt $\% / w t \%)$. Twenty microliters of the mixed solution was cast on a Teflon plate and dried overnight at room temperature. These casein-SiNSi hybrid materials were stripped from the plate and washed with water. The amount of casein in the hybrid material was determined as follows: the casein-SiNSi hybrid material was dissolved in a 1-M NaOH solution and quantified by absorption at $280 \mathrm{~nm}$ using a U-0080D photodiode array bio-spectrophotometer (Hitachi Ltd., Tokyo, Japan).

The water stability in an aqueous solution of the casein-SiNSi hybrid material was confirmed by the following method. The casein-SiNSi hybrid materials were incubated in ultrapure water $(5 \mathrm{ml})$. The absorbance at $280 \mathrm{~nm}$ of the solution for various time intervals was measured, and the eluted amount of casein from the hybrid material was determined by Equation (1).

Eluted amount of casein $=\frac{(\text { Amount of casein in incubated solution })}{(\text { Total amount of casein in hybrid material })} \times 100$

The P element, related to the phosphate group in casein, was analyzed by inductively coupled plasma atomic emission spectrophotometry (ICPS-7000 Ver. 2, Shimadzu Corp., Kyoto, Japan). The amount of the carboxylate group in casein was estimated from the Protein Data Bank.

\section{Structural analyses of the casein-SiNSi hybrid material and the metal ion-accumulated casein-SiNSi hybrid material}

The IR absorption spectra of the casein-SiNSi hybrid material were measured using the attenuated total reflection method with a diamond prism using a FT-IR 8400 Fourier transform infrared spectrometer (Shimadzu Corp.). The IR spectra were measured with a resolution of $4 \mathrm{~cm}^{-1}$.

The metal ion-accumulated casein-SiNSi hybrid materials were prepared by the incubation of the hybrid film into a metal ion-containing aqueous solution with various concentrations (0-500 p.p.m.) for $24 \mathrm{~h}$. These metal ion-accumulated hybrid films were washed with ultrapure water $(50 \mathrm{ml} \times 3$ times $)$ and dried overnight at room temperature. These metal ion-accumulated hybrid films were analyzed by the attenuated total reflection method with a diamond prism using an IR spectrometer.

\begin{abstract}
Accumulation of metal ions by the casein-SiNSi hybrid material Copper(II) chloride, zinc(II) chloride, chromium(III) chloride, aluminum chloride, calcium chloride, magnesium chloride, yttrium(III) chloride, lanthanum(III) chloride and indium(III) chloride were dissolved in ultrapure water. The concentrations of the aqueous metal ion solutions were 0-200 p.p.m. The accumulation of the metal ions by the casein-SiNSi hybrid material was demonstrated as follows: one casein-SiNSi hybrid film was added to a metal ion-containing aqueous solution $(1 \mathrm{ml})$, which was stirred at room temperature, and then the hybrid film was separated from the aqueous solution. The accumulated amount of the metal ions was determined by the absorbance of the aqueous solutions in the absence or presence of the casein-SiNSi hybrid material. The concentration of the aqueous metal ion solution was estimated from the calibration curve with the metal indicator xylenol orange or methylthymol blue. ${ }^{14,21}$
\end{abstract}

Reuse of metal ion-accumulated casein-SiNSi hybrid material The procedure for the reuse of the metal ion-accumulated casein-SiNSi hybrid material was as follows: the $\mathrm{Cu}(\mathrm{II})$ ion-, $\mathrm{Cr}(\mathrm{III})$ ion- or $\mathrm{Mg}$ (II) ion-accumulated
casein-SiNSi hybrid material was washed with a $1 \mathrm{~mm}$ EDTA solution $(25 \mathrm{ml})$ and ultrapure water $(25 \mathrm{ml} \times 5$ times $)$. The washed casein-SiNSi hybrid material was added to the metal ion-containing aqueous solution. A similar washing procedure was followed using $0.1 \mathrm{~m}$ hydrochloric acid. The concentration of the $\mathrm{Cu}(\mathrm{II})$ ion, $\mathrm{Cr}$ (III) ion or $\mathrm{Mg}$ (II) ion was 20 p.p.m. This cycle was repeated four times.

\section{RESULTS AND DISCUSSION}

\section{Preparation of casein-SiNSi hybrid material}

The casein-SiNSi hybrid material was prepared by mixing casein and the silane coupling reagent, bis(trimethoxysilylpropyl)amine (SiNSi). The mixing ratio of casein/SiNSi was varied from 100:0 (wt $\% / w t \%)$ to 30:70 (wt\%/wt \%). Figure 1a shows a photograph of the casein-SiNSi (30:70) hybrid material. This casein-SiNSi hybrid material is a transparent film with a thickness of $\sim 100 \mu \mathrm{m}$. The dried casein-SiNSi hybrid film under $50 \%$ relative humidity was not flexible and was cracked when bent. The swollen casein-SiNSi hybrid film in water was flexible and did not crack, even when bent to an angle $>90^{\circ}$. In addition, although the bending process was repeated, the swollen casein-SiNSi hybrid film did not break. In contrast, the casein film without hybridization of the inorganic components, such as the silane coupling reagent, immediately dissolved in water and could not be used as an environmental material. Therefore, we demonstrated the water stability of the casein-SiNSi hybrid material.

Figure 2 shows the water stability of the casein-SiNSi hybrid materials with different SiNSi mixing ratios. The casein-SiNSi (70:30) hybrid material was unstable because it immediately dissolved in water. The casein-SiNSi hybrid material with a mixing ratio of 50:50 indicated good water stability. The amount of eluted casein from the hybrid material increased with the incubation time and reached a constant value at $1 \mathrm{~h}$. In addition, the water stability increased with the SiNSi mixing ratio. The casein-SiNSi (30:70) hybrid material showed nearly no elution of casein from the hybrid material. Therefore, the casein-SiNSi (30:70) hybrid materials were stored in ultrapure water for several hours to remove the small amount of water-soluble components and were then used for further experiments.

\section{Structural analysis of casein-SiNSi hybrid material}

Figure 3 shows the IR spectra of (a) the casein material without the hybridization of SiNSi, (b) the casein-SiNSi (70:30) hybrid material, (c) the casein-SiNSi (30:70) hybrid material and (d) the dried SiNSi material. Generally, the trimethoxysilyl group, such as $-\mathrm{Si}\left(\mathrm{OCH}_{3}\right)_{3}$, is stepwise hydrolyzed in water to give the corresponding silanols, which

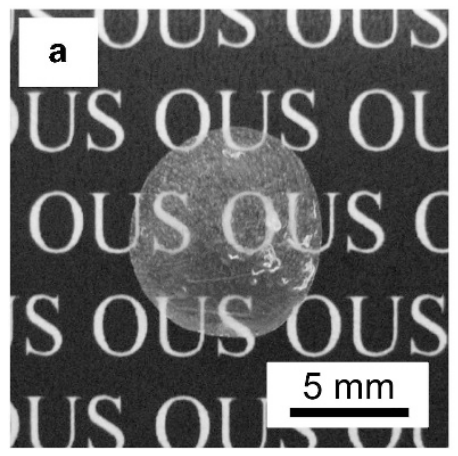

\section{b}

Figure 1 Photograph of the casein-SiNSi (30:70) hybrid material. (a) Dried hybrid casein-SiNSi material and (b) $\mathrm{Cu}(\mathrm{II})$ ion-accumulated casein-SiNSi hybrid material in an aqueous solution. The thickness of the hybrid material under dryness was $\sim 100 \mu \mathrm{m}$. A full color version of this figure is available at Polymer Journal online. 


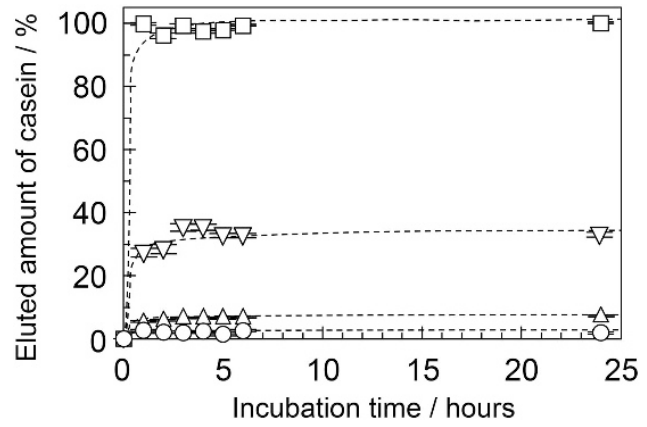

Figure 2 Stability of casein-SiNSi hybrid material in water. ( $\square$ )casein-SiNSi (70:30) hybrid material; $(\nabla)$ casein-SiNSi $(60: 40)$ hybrid material; $(\Delta)$ casein-SiNSi (50:50); (O) casein-SiNSi (30:70) hybrid material. The eluted casein from a casein-SiNSi hybrid material was quantified by its absorbance at $280 \mathrm{~nm}$. Each value represents the mean of three separate determinations \pm s.d.



Figure 3 IR spectra of casein-SiNSi hybrid material. (a) Casein material without the hybridization of SiNSi; (b) casein-SiNSi (70:30) hybrid material; (c) casein-SiNSi (30:70) hybrid material; and (d) dried SiNSi material. The dotted lines at $1234 \mathrm{~cm}^{-1}$ and $2930 \mathrm{~cm}^{-1}$ show the absorption bands that are related to the antisymmetric vibration of the phosphate group and the symmetric stretching vibration of the secondary ammonium salt, respectively. The IR spectra at $2000-2400 \mathrm{~cm}^{-1}$ were omitted because only the absorption band related to carbon dioxide appeared. The scale bars indicate the value of transmittance. The IR spectrum was measured at a resolution of $4 \mathrm{~cm}^{-1}$. Triplicate experiments yielded similar results.

ultimately condense to siloxanes, such as $\mathrm{Si-O}-\mathrm{Si}$ groups, with a threedimensional network. ${ }^{22}$ The formation of the $\mathrm{Si}-\mathrm{O}-\mathrm{Si}$ groups through the sol-gel process has been reported for various organic-inorganic hybrid materials with the silane coupling reagents. ${ }^{13,14,23,24}$ In our research, the stretching vibration of the $\mathrm{Si}-\mathrm{O}-\mathrm{Si}$ group ${ }^{13,14,23,24}$ at $1000-1200 \mathrm{~cm}^{-1}$ appeared due to the hybridization of SiNSi. These results suggested that the three-dimensional siloxane network of SiNSi encapsulates the casein molecule in its network.

In the casein material, the absorption band at $1234 \mathrm{~cm}^{-1}$, related to the antisymmetric vibration of the phosphate group, , $^{6,13,25,26}$ appeared (dotted line in Figure 3). This absorption band was shifted to a lower wavenumber by hybridization with SiNSi (spectrum (c) in Figure 3). In addition, the absorption band at $2930 \mathrm{~cm}^{-1}$, attributed to the symmetric stretching vibration of the secondary ammonium salt, ${ }^{25}$ appeared and increased by the hybridization with casein and SiNSi (dotted line in Figure 3). These results suggested that the secondary amine, the $-\mathrm{NH}$ - group, of the SiNSi molecule formed a secondary ammonium salt, the $-\mathrm{NH}_{2}{ }^{+}-$group, by protonation, and the

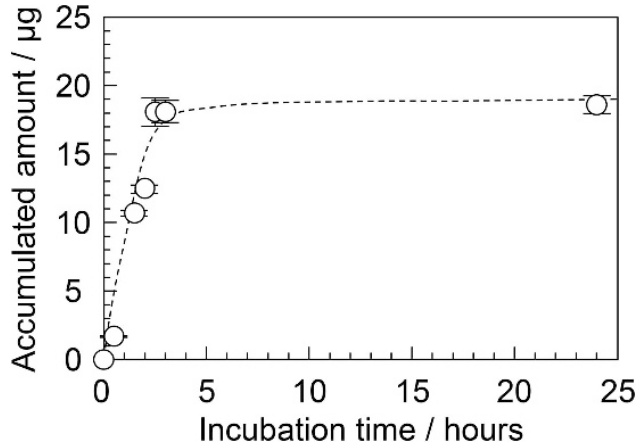

Figure 4 The accumulation of $\mathrm{Cu}(\mathrm{II})$ ions by the casein-SiNSi hybrid material for various incubation times. The concentration of the $\mathrm{Cu}(\mathrm{II})$ ions was 20 p.p.m. The accumulated amounts of the $\mathrm{Cu}(\mathrm{II})$ ion were estimated from the calibration curve with the metal indicator xylenol orange. Each value represents the mean of three separate determinations \pm s.d.

casein-SiNSi hybrid material was formed by the electrostatic interactions between the phosphate group of the casein and the $-\mathrm{NH}_{2}{ }^{+}$- group of the SiNSi molecule. In addition, as previously described, the casein material was encapsulated into the threedimensional siloxane network of SiNSi. As a result, the casein-SiNSi hybrid materials showed a water-insoluble property. Similar phenomena, such as the water stabilization by encapsulation and the electrostatic interaction, have been reported for various organic-inorganic hybrid materials. ${ }^{13,14,16}$

Accumulation of metal ions by the casein-SiNSi hybrid material The casein-SiNSi hybrid material was stable in water. Therefore, we demonstrated the accumulation of metal ions by the casein-SiNSi hybrid material. When the casein-SiNSi hybrid material was incubated in an aqueous $\mathrm{Cu}(\mathrm{II})$ ion-containing solution for $24 \mathrm{~h}$, the hybrid material turned blue owing to the accumulation of $\mathrm{Cu}(\mathrm{II})$ ions. Figure $1 \mathrm{~b}$ is a photograph of the blue casein-SiNSi hybrid film stained with $\mathrm{Cu}(\mathrm{II})$ ions. The casein-SiNSi hybrid material, which was stained by the $\mathrm{Cu}$ (II) ions, did not show any release of the $\mathrm{Cu}$ (II) ions into the water. However, although the dried SiNSi material without the mixing of casein was incubated in the $\mathrm{Cu}(\mathrm{II})$ ion-containing solution for $24 \mathrm{~h}$, it did not show any color change. These results suggested that the casein molecule in the casein-SiNSi hybrid material has the ability to accumulate $\mathrm{Cu}(\mathrm{II})$ ions.

We estimated the accumulation time of the metal ions by the casein-SiNSi hybrid material. Figure 4 shows the accumulated amount of $\mathrm{Cu}(\mathrm{II})$ ions with various incubation times by the casein-SiNSi hybrid material. The $\mathrm{Cu}(\mathrm{II})$ ion concentration was 20 p.p.m. As a result, the accumulated amount of the $\mathrm{Cu}$ (II) ions increased with the incubation time and reached a constant value at $3 \mathrm{~h}$. Similar results were obtained for the different $\mathrm{Cu}(\mathrm{II})$ ion concentrations. Therefore, we demonstrated the accumulation of metal ions for the incubation time of $3 \mathrm{~h}$.

Figure 5 shows the accumulation of $(\bigcirc) \mathrm{Cu}(\mathrm{II})$ ions, $(\Delta) \mathrm{Mg}$ (II) ions and ( $\square$ ) $\mathrm{La}(\mathrm{III})$ ions at various concentrations by the casein-SiNSi hybrid material. The accumulated amount of the metal ions increased with the concentration and reached a constant value at 100 p.p.m. Therefore, we defined the constant value as the maximum accumulated amount of the metal ions by the casein-SiNSi hybrid material. The maximum accumulated amounts of $\mathrm{Cu}$ (II) ions, $\mathrm{Mg}$ (II) ions and $\mathrm{La}(\mathrm{III})$ ions were 22,12 and $3 \mu \mathrm{g}$, respectively. As a result, the casein-SiNSi hybrid material more selectively accumulated the heavy 


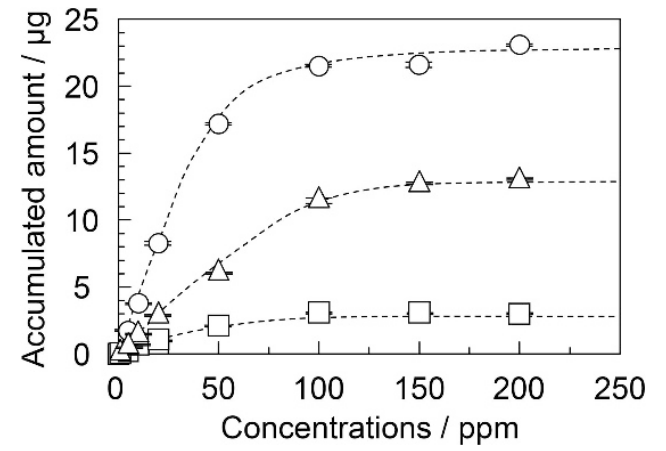

Figure 5 Accumulation of $(O) \mathrm{Cu}(\mathrm{II})$ ion, $(\Delta) \mathrm{Mg}(\mathrm{II})$ ion and $(\square) \mathrm{La}(\mathrm{III})$ ion by the casein-SiNSi hybrid material for various concentrations. The concentrations were $0-200$ p.p.m. The incubation time was $3 \mathrm{~h}$. The accumulated amounts of the metal ions were estimated from the calibration curve with the metal indicator xylenol orange or methylthymol blue. Each value represents the mean of three separate determinations \pm s.d.

and light metal ions compared with the rare-earth metal ions, such as the $\mathrm{La}(\mathrm{III})$ ion.

We next calculated the molar ratio of casein and the accumulated metal ions at the maximum accumulated amount. The molar value of casein was calculated based on the phosphate and carboxylate groups. The amounts of the phosphate and carboxylate groups in the casein were determined by inductively coupled plasma analysis and the Protein Data Bank, respectively. The molar ratio of casein (phosphate and carboxylate groups) and the accumulated metal ions was calculated by the following equation:

$$
\text { molar ratio }=\frac{\text { (the mole of maximum }}{\text { accumulated metal ion })}
$$

Table 1 shows the molar ratio of casein (phosphate and carboxylate groups) and metal ions for the maximum accumulated amount. The calculated molar ratios for the maximum accumulated amount indicated different values for the different metal ions. The molar ratio of the casein and metal ions ranged from 1:0.003 to 1:0.08. These values suggest that the higher molar ratios strongly interact with the metal ions. The binding affinities between the casein-SiNSi hybrid material and the metal ions were $\mathrm{Mg}$ (II) $>\mathrm{Ca}(\mathrm{II})>\mathrm{Al}(\mathrm{III}) \gg \mathrm{Cu}(\mathrm{II})$ $>\mathrm{Cr}(\mathrm{III})>\mathrm{Zn}(\mathrm{II}) \gg \mathrm{In}(\mathrm{III})>\mathrm{Y}(\mathrm{III})>\mathrm{La}(\mathrm{III})$. These results suggested that the casein-SiNSi hybrid material selectively accumulates the heavy and light metal ions. In addition, the hybrid material could not accumulate the rare-earth metal ions, such as the $\mathrm{La}(\mathrm{III})$ ions and Y(III) ions. However, the valence of the metal ion did not affect the accumulation by the casein-SiNSi hybrid material.

The order of the ionic radii of the metal ions is $\mathrm{Al}(\mathrm{III})<\mathrm{Cr}$ (III) $<\mathrm{Cu}(\mathrm{II}), \mathrm{Zn}$ (II) $<\mathrm{Mg}$ (II) $<\mathrm{In}(\mathrm{III})<\mathrm{Y}(\mathrm{III})<\mathrm{Ca}(\mathrm{II})<\mathrm{La}(\mathrm{III}) .{ }^{27,28}$ Although the affinity of the light metal ions to the casein-SiNSi hybrid material, such as the $\mathrm{Al}(\mathrm{III}), \mathrm{Mg}(\mathrm{II})$ and $\mathrm{Ca}(\mathrm{II})$ ions did not depend on the ionic radii, the affinity of the heavy metal and rare-earth metal ions was generally consistent with the ionic radii of the metal ions. These results suggested that the heavy metal ions and light metal ions interact with the different binding sites of casein. Therefore, we examined the IR measurements of the metal ion-accumulated casein-SiNSi hybrid material to discuss the accumulative mechanism used by the hybrid material for the heavy and light metal ions.
Table 1 Molar ratios of casein (phosphate and carboxylate groups) and various metal ions

\begin{tabular}{lc}
\hline Metal ion & Casein: metal ion \\
\hline $\mathrm{Cu}(I I)$ & $1: 0.056$ \\
$\mathrm{Zn}(\mathrm{II})$ & $1: 0.029$ \\
$\mathrm{Cr}(I I I)$ & $1: 0.039$ \\
$\mathrm{Mg}(\mathrm{II})$ & $1: 0.084$ \\
$\mathrm{Al}(\mathrm{III})$ & $1: 0.073$ \\
$\mathrm{Ca}(\mathrm{II})$ & $1: 0.079$ \\
$\mathrm{La}(\mathrm{III})$ & $1: 0.0034$ \\
$\mathrm{Y}(\mathrm{III})$ & $1: 0.0043$ \\
$\operatorname{In}(\mathrm{III})$ & $1: 0.022$ \\
\hline
\end{tabular}

${ }^{a}$ The moles of the accumulated metal ions were estimated from the maximum accumulated amount.

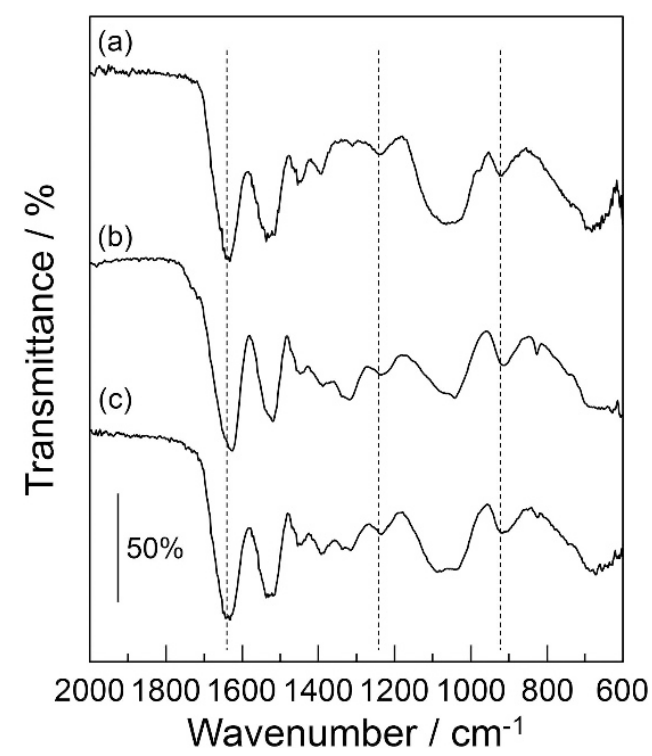

Figure $6 \mathrm{IR}$ spectra of (a) casein-SiNSi hybrid material, (b) $\mathrm{Mg}(\mathrm{II})$ ion-accumulated casein-SiNSi hybrid material and (c) $\mathrm{Cu}(\mathrm{II})$ ionaccumulated casein-SiNSi hybrid material. The concentrations of the metal ions were 500 p.p.m. The dotted lines at $920 \mathrm{~cm}^{-1}, 1234 \mathrm{~cm}^{-1}$ and $1640 \mathrm{~cm}^{-1}$ show the absorption bands that are related to the symmetric vibration of the phosphate group, the antisymmetric vibration of the

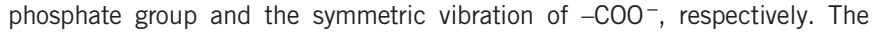
scale bar indicates the value of transmittance. The material used was the casein-SiNSi (30:70) hybrid material. The IR spectrum was measured at a resolution of $4 \mathrm{~cm}^{-1}$. Triplicate experiments yielded similar results.

IR measurements of the metal ion-accumulated casein-SiNSi hybrid material

Figures $6 a-c$ show the IR spectra of the casein-SiNSi (30:70) hybrid material without the accumulation of metal ions, the $\mathrm{Mg}(\mathrm{II})$ ion-accumulated casein-SiNSi hybrid material, and the $\mathrm{Cu}(\mathrm{II})$ ion-accumulated casein-SiNSi hybrid material, respectively. The metal ion-accumulated hybrid samples were prepared by the incubation of the casein-SiNSi hybrid materials in an aqueous $\mathrm{Mg}$ (II) ion- or $\mathrm{Cu}(\mathrm{II})$ ion-containing solution. The concentration of the metal ions was 500 p.p.m. The casein-SiNSi hybrid material without the accumulation of metal ions had an absorption band at $1640 \mathrm{~cm}^{-1}$, related to the symmetric stretching vibration of $-\mathrm{COO}$ which arises from glutamic or aspartic acids. ${ }^{16,25,29,30}$ When the casein-SiNSi hybrid material accumulated the $\operatorname{Mg}(\mathrm{II})$ ions, this absorption band at $1640 \mathrm{~cm}^{-1}$ 
shifted to a lower wavenumber, $\sim 10 \mathrm{~cm}^{-1}$ (spectrum (b) in Figure 6). A similar phenomenon, that is, the shift to a lower wavenumber, was obtained for the absorption bands at $1234 \mathrm{~cm}^{-1}$ and $920 \mathrm{~cm}^{-1}$, attributed to the antisymmetric and symmetric stretching vibrations of the phosphate group, respectively. ${ }^{6,13,25,26}$ These shifts in the absorption band to a lower wavenumber by the accumulation of metal ions have been reported for various absorbents of metal ions. ${ }^{14,21,31}$ These results suggested that the $\mathrm{Mg}$ (II) ion interacts with not only the $-\mathrm{COO}^{-}$group but also the phosphate group of the casein-SiNSi hybrid material.

Similar measurements were performed using the $\mathrm{Cu}(\mathrm{II})$ ion-accumulated casein-SiNSi hybrid material. When the casein-SiNSi hybrid material accumulated the $\mathrm{Cu}(\mathrm{II})$ ion, the absorption band at $1640 \mathrm{~cm}^{-1}, 16,25,29,30$ which is the stretching vibration of $-\mathrm{COO}^{-}$, did not show any shift in wavenumber. In contrast, the absorption bands at $1234 \mathrm{~cm}^{-1}$ and $920 \mathrm{~cm}^{-1}$, which are the stretching vibrations of the phosphate group, $6,13,25,26$ slightly shifted to a lower wavenumber and broadened owing to the accumulation of $\mathrm{Cu}$ (II) ions. These results suggested that the $\mathrm{Cu}$ (II) ions interact with the phosphate group of the casein-SiNSi hybrid material, although the $\mathrm{Cu}$ (II) ions do not strongly interact with the $-\mathrm{COO}^{-}$group. As a result, the differences in the accumulative mechanism between light metal ions, such as the $\mathrm{Mg}$ (II) ions, and heavy metal ions, such as the $\mathrm{Cu}(\mathrm{II})$ ions, for the casein-SiNSi hybrid material appeared to be due to the binding affinity of the metal ions (Table 1).

\section{Reuse of metal ion-accumulated casein-SiNSi hybrid material}

Finally, we demonstrated the reuse of the metal ion-accumulated casein-SiNSi hybrid material. Generally, because a chelating reagent, such as EDTA, strongly interacts with metal ions, the chelating reagents can remove the metal ions from a metal ion-accumulated substrate. $^{32,33}$ Therefore, we examined the reuse of the metal ion-accumulated casein-SiNSi hybrid material by washing with an aqueous EDTA solution. Figure 7 a shows the reuse of the $\mathrm{Cr}$ (III) ion-accumulated casein-SiNSi hybrid material. Before the reuse, the casein-SiNSi hybrid material had accumulated $\sim 12 \mu \mathrm{g}$ of $\mathrm{Cr}$ (III) ions. Although the casein-SiNSi hybrid material was reused four times by washing with the aqueous EDTA solution, the accumulated amount of $\mathrm{Cr}$ (III) ion was maintained at $\sim 12 \mathrm{mg}$ and did not appear to decrease. This result indicated that the metal ion-accumulated casein-SiNSi hybrid material could be reused by washing with an aqueous EDTA solution. Similar results were obtained for the $\mathrm{Mg}(\mathrm{II})$ ion-accumulated and $\mathrm{Cu}(\mathrm{II})$ ion-accumulated casein-SiNSi hybrid materials (data not shown).

However, calcium ion-binding casein is known to release calcium ions under a low $\mathrm{pH}$ condition. ${ }^{1,34}$ In addition, the peptide bond, which is part of the protein, is a relatively stable bond under a low $\mathrm{pH}$ condition. Therefore, we examined the reuse of the metal ion-accumulated casein-SiNSi hybrid material by washing with hydrochloric acid. Figure $7 \mathrm{~b}$ shows the $\mathrm{Cr}$ (III) ion-accumulated casein-SiNSi hybrid material after washing with hydrochloric acid. As a result, although the casein-SiNSi hybrid material was reused four times, the accumulated amount of $\mathrm{Cr}$ (III) ion did not appear to decrease. Similar phenomena were obtained for the $\mathrm{Mg}(\mathrm{II})$ ion-accumulated and $\mathrm{Cu}(\mathrm{II})$ ion-accumulated casein-SiNSi hybrid materials (data not shown). These results suggested that the metal ion-accumulated hybrid material could be reused by washing with an aqueous EDTA solution or hydrochloric acid.
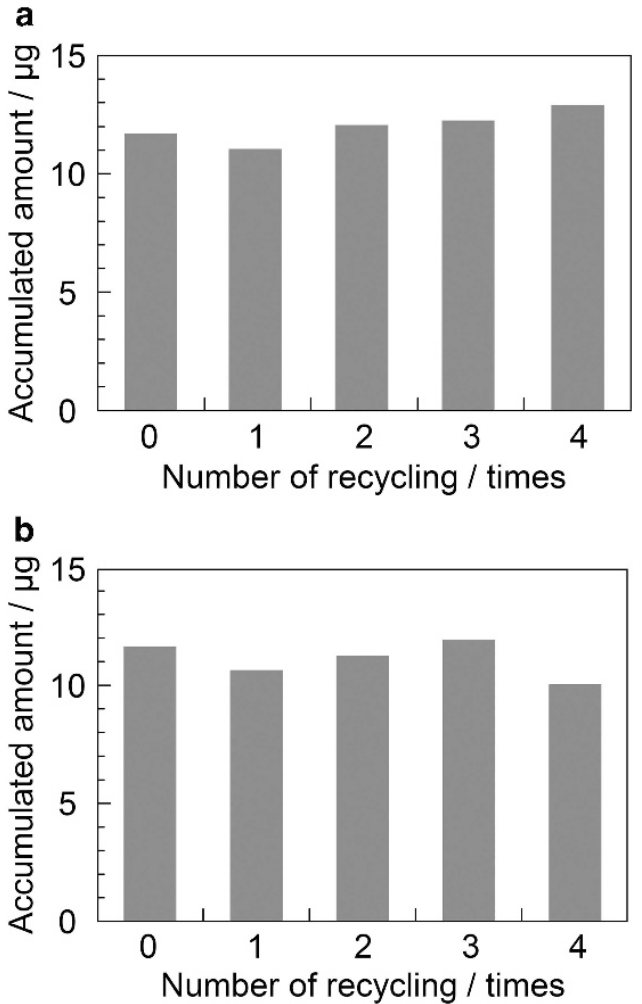

Figure 7 Reuse of $\mathrm{Cr}(\mathrm{III})$ ion-accumulated casein-SiNSi hybrid materials by washing with (a) $1 \mathrm{mM}$ aqueous EDTA solution and (b) $0.1 \mathrm{~m}$ hydrochloric acid solution. The concentration of the $\mathrm{Cr}(\mathrm{III})$ ion was 20 p.p.m. The accumulated amounts of the $\mathrm{Cr}(\mathrm{III})$ ion were estimated from the calibration curve with the metal indicator xylenol orange. Triplicate experiments yielded similar results.

\section{CONCLUSION}

We prepared a casein-SiNSi hybrid material by mixing casein and a silane coupling reagent (SiNSi). These casein-SiNSi hybrid materials showed good water stability through encapsulation into the three-dimensional siloxane network and through electrostatic interactions. In addition, the casein-SiNSi hybrid material could accumulate various metal ions from an aqueous solution. The hybrid materials showed ion selectivity for heavy and light metal ions. In addition, the metal ion-accumulated hybrid materials could be recycled by washing them with an aqueous EDTA solution or hydrochloric acid. The casein-SiNSi hybrid material may have potential use in environmental applications, such as the detoxification of harmful metal ions from drinking water, river water and industrial waste.

\section{CONFLICT OF INTEREST}

The authors declare no conflict of interest.

\section{ACKNOWLEDGEMENTS}

This work was supported by JSPS KAKENHI Grant Number 25410195 and the matching fund subsidy for private universities from MEXT. We acknowledge Kake Educational Institution for the inductively coupled plasma analysis.

\footnotetext{
1 Sutermeister, E. \& Browne, F. L. Casein and its Industrial Applications (Reinhold, New York, NY, USA, 1939).

2 Brother, G. H. Plastic materials from farm products. Ind. Eng. Chem. 31, 145-148 (1939).
} 
3 Brother, G. H. Casein plastics. Ind. Eng. Chem. 32, 31-33 (1940).

4 Kozempel, M. \& Tomasula, P. M. Development of a continuous process to make casein films. J. Agric. Food Chem. 52, 1190-1195 (2004).

5 Yannai, S. \& Sachs, K. M. Absorption and accumulation of cadmium, lead and mercury from foods by rats. Food Chem. Toxicol. 31, 351-355 (1993).

6 Pomastowski, P., Sprynskyy, M. \& Buszewski, B. The study of zinc ions binding to casein. Colloid Surf. B Biointerfaces 120, 21-27 (2014).

7 Mata, L., Sanchez, L. \& Calvo, M. Interaction of mercury with human and bovine milk proteins. Biosci. Biotechnol. Biochem. 61, 1641-1645 (1997).

8 Mishra, S. P., Tiwari, D., Dubey, R. S. \& Mishra, M. Biosorptive behaviour of casein for $\mathrm{Zn}^{2+}, \mathrm{Hg}^{2+}$ and $\mathrm{Cr}^{3+}$ : effects of physico-chemical treatments. Bioresour. Technol. 63, $1-5$ (1998).

9 Kandimalla, V. B. \& Ju, H. Binding of acetylcholinesterase to multiwall carbon nanotube-cross-linked chitosan composite for flow-injection amperometric detection of an organophosphorous insecticide. Chem. Eur. J. 12, 1074-1080 (2006).

10 Novak, B. M. Hybrid nanocomposite materials-between inorganic glasses and organic polymers. Adv. Mater. 5, 422-433 (1993).

11 Uragami, T., Katayama, T., Miyata, T., Tamura, H., Shiraiwa, T. \& Higuchi, A. Dehydration of an ethanol/water azeotrope by novel organic-inorganic hybrid membranes based on quaternized chitosan and tetraethoxysilane. Biomacromolecules 5, 1567-1574 (2004).

12 Satoh, S., Fugetsu, B., Nomizu, M. \& Nishi, N. Functional DNA-silica composite prepared by sol-gel method. Polym. J. 37, 94-101 (2005).

13 Yamada, M. \& Aono, H. DNA-inorganic hybrid material as selective absorbent for harmful compounds. Polymer 49, 4658-4665 (2008).

14 Yamada, M. \& Shiiba, S. Preparation of pectin-inorganic composite material as accumulative material of metal ions. J. Appl. Polym. Sci. 132, 42056-42062 (2015).

15 Honma, I., Nakajima, H., Nishikawa, O., Sugimoto, T. \& Nomura, S. Organic/inorganic nano-composites for high temperature proton conducting polymer electrolytes. Solid State lonics 162-163, 237-245 (2003).

16 Yamada, M. \& Ogino, T. Anhydrous proton conductor consisting of pectin-inorganic composite material. J. Appl. Polym. Sci. 132, 42433-42439 (2015).

17 Toskas, G., Cherif, C., Hund, R. D., Laourine, E., Mahltig, B., Fahmi, A., Heinemann, C. \& Hanke, T. Chitosan(PEO)/silica hybrid nanofibers as a potential biomaterial for bone regeneration. Carbohydr. Polym. 94, 713-722 (2013).
18 Avnir, D., Coradin, T., Lev, O. \& Livage, J. Recent bio-applications of sol-gel materials. J. Mater. Chem. 16, 1013-1030 (2006).

19 Monton, M. R. N., Forsberg, E. M. \& Brennan, J. D. Tailoring sol-gel-derived silica materials for optical biosensing. Chem. Mater. 24, 796-811 (2012).

20 Chernev, G., Rangelova, N., Djambazki, P., Nenkova, S., Salvado, I., Fernandes, M., Wu, A. \& Kabaivanova, L. Sol-gel silica hybrid biomaterials for application in biodegradation of toxic compounds. J. Sol-Gel Sci. Technol. 58, 619-624 (2011).

21 Yamada, M. \& Abe, K. Selective accumulation of rare earth metal and heavy metal ions by a DNA-inorganic hybrid material. Polym. J. 46, 366-371 (2014).

22 Plueddemann, E. P. Silane Coupling Agents. 2nd edn (Plenum Press, New York, NY, USA, 1991).

23 Vince, J., Orel, B., Vilčnik, A., Fir, M., Vuk, A. Š., Jovanovski, V. \& Simončič, B. Structural and water-repellent properties of a urea/poly(dimethylsiloxane) sol-gel hybrid and its bonding to cotton fabric. Langmuir 22, 6489-6497 (2006).

24 Martínez, Y., Retuert, J., Yazdani-Pedram, M. \& Cölfen, H. Hybrid ternary organicinorganic films based on interpolymer complexes and silica. Polymer 45, 3257-3265 (2004).

25 Silverstein, R. M. \& Webster, F. X. Spectrometric Identification of Organic Compounds (John Wiley \& Sons, New York, NY, USA, 1998).

26 Greish, Y. E. \& Brown, P. W. Formation and properties of hydroxyapatite-calcium poly (vinyl phosphonate) composites. J. Am. Ceram. Soc. 85, 1738-1744 (2002).

27 King, R. B. Encyclopedia of Inorganic Chemistry, (John Wiley \& Sons, Chichester, UK, 1994).

28 Cotton, F. A. \& Wilkinson, G. Advanced Inorganic Chemistry: a Comprehensive Text, (John Wiley \& Sons, New York, NY, USA, 1980).

29 Yamada, M. \& Moritani, Y. Polypeptide for anhydrous proton conductor. Electrochim. Acta 144, 168-173 (2014).

30 Shi, L. \& Gunasekaran, S. Preparation of pectin-ZnO nanocomposite. Nanoscale Res. Lett. 3, 491-495 (2008).

31 Katseva, G. N., Kukhta, E., Panova, É. P. \& Ghirva, V. Y. Interaction of pectin substances with copper, mercury, zinc, and cadmium salts. Chem. Nat. Compd. 24, 142-146 (1988).

32 Lippard, S. J. \& Berg, J. M. Principles of Bioinorganic Chemistry (University of Science Books, Mill Valley, 1994).

33 Lo, I. M. C. \& Yang, X. Y. EDTA extraction of heavy metals from different soil fractions and synthetic soils. Water Air Soil Pollut. 109, 219-236 (1999).

34 Hippel, P. H. \& Waugh, D. F. Casein: monomers and polymers. J. Am. Chem. Soc. 77, 4311-4319 (1955). 